\title{
KEANEKARAGAMAN MAKROZOOBENTOS DAN HUBUNGANNYA DENGAN PENUTUPAN PADANG LAMUN (SEAGRASS) DI PERAIRAN MANDAILING NATAL SUMATERA UTARA
}

\author{
Pera Herawati1, Ternala A. Barus ${ }^{2}$, Hesti Wahyuningsih ${ }^{3}$ \\ Fakultas Matematika dan Ilmu Pengetahuan Alam, USU, Medan \\ pera_belong@yahoo.co.id
}

\begin{abstract}
ABSTRAK
Penelitian ini tentang keanekaragaman makrozoobentos dan hubungannya dengan penutupan padang lamun di perairan Natal Mandailing Natal Sumatera Utara, telah dilakukan pada bulan Mei-Juni 2016. Lokasi Penelitian di tetapkan sebanyak 4 stasiun dengan metode purposive sampling menggunakan transek kuadrat $1 \mathrm{x} 1 \mathrm{~m}$ sebanyak 5 kali ulangan. Penelitian ini ditemukan 4 spesies lamun yaitu Enhalus acoroides, Halophila ovalis, Cymodecea rotundata, Halodule pinifolia dengan persentase tutupan lamun pada stasiun I (47\%), stasiun II (29\%), stasiun III (76,6\%), dan stasiun IV (83,8\%). Makrozoobentos yang ditemukan ada 16 spesies yang dikelompokkan menjadi 7 kelas yaitu Gastropoda, Bivalvia, Echinoidea, Holothuroidea, Malacostraca, Amphineura, Anthozoa. Nilai kepadatan tertinggi diperoleh dari kelas Bivalvia pada stasiun I spesies Anadara Inaequivalvalis sebesar 1,2 ind $/ \mathrm{m}^{2}$. Hasil analisis menunjukkan tingkat keanekaragaman tergolong sedang. Hasil analisis korelasi Person antara keanekaragaman makrozoobentos dengan tutupan lamun bernilai -0,949 ini berarti hubungan antara tutupan lamun dengan keanekaragaman makrozoobentos di kawasan perairan Natal kuat berlawanan arah. Tingginya persentase tutupan lamun tidak selalu diikuti oleh tingginya keanekaragaman makrozoobentos dikawasan tersebut.
\end{abstract}

Kata kunci: persentase tutupan lamun, makrozoobentos, Mandailing Natal

\section{DIVERSITY OF MACROZOOBENTHOS AND ITS RELATION TO THE SEAGRASS COVER IN THE WATERS OF THE MANDAILING NATAL OF NORTH SUMATERA}

\begin{abstract}
This research about the diversity of macrozoobenthos and its relation to the seagrass cover in the natal waters of Mandailing Natal north Sumatera, have been done on May-June 2016. The research location was determined by 4 stations with purposive sampling method using $1 \times 1 \mathrm{~m}$ quadratic transect 5 times the repetition. This study found 4 species of seagrass is Enhalus acoroides, Halophila ovalis, Cymodecea rotundata, Halodule pinifolia with percentage of seagrass cover at station 1 (47\%), station II $(29 \%)$, station III $(76,6 \%)$, and station IV $(83,8 \%)$. Macrozoobenthos found in 16 species grouped in to 7 classes namely gastropods, bivalves, echinoidea, holothuroidea, malacostraca, amphineura, anthozoa. The highest density valves were obtained from bivalves class at the Anadara Inaequivalvalis station of $1,2 \mathrm{ind} / \mathrm{m}^{2}$.The results show that diversity levels are classified as medium diversity. The results correlation analysis of person between seagrass cover with macrozoobenthos diversity is valuable $-0,949$ its mean the relationship between seagrass cover with macrozoobenthos diversity this region is strong in opposite direction. The highest percentage of seagrass is not always followed by the highest diversity of macrozoobenthos in the region.
\end{abstract}

Keyword : percentage of seagrass cover, macrozoobenthos, Mandailing Natal

\section{Pendahuluan}

Lamun adalah tumbuhan berbunga yang telah menyesuaikan diri hidup di laut dangkal. Lamun merupakan salah satu lingkungan yang mampu memberikan dukungan habitat bagi makrozoobentos. Pantai Natal terletak di Kecamatan Natal Kabupaten Mandailing Sumatera Utara merupakan kawasan pantai yang cukup panjang kira-kira 170 km, luas laut kira-kira 3.778,08 km² (Dinas 
Kelautan dan Perikanan Mandaling Natal, 2002). Pantai Natal memiliki perairan jenih dengan hamparan padang lamun yang cukup luas.

Pantai Natal mempunyai substrat lumpur-berpasir yang cocok untuk tumbuh lamun. Menurut Hendra (2011) hampir semua tipe substrat dapat ditumbuhi lamun, namun padang lamun yang luas ditemukan di substrat lumpur-berpasir. Kondisi ini memungkinkan beragamnya komunitas makrozoobentos yang hidup di padang lamun. Tujuan penelitian ini mengetahui keane-karagaman makrozoobentos dan hubungannya dengan penutupan padang lamun di perairan Natal Mandailing Natal Sumatera Utara.

\section{Bahan dan Metode \\ Lokasi dan waktu Penelitian}

Lokasi penelitian terletak di pantai Natal Kecamatan Natal Kabupaten Mandailing Natal Sumatera Utara. Penelitian dilaksanakan bulan April-Juni 2016. Lokasi penelitian ditetapkan sebanyak 4 stasiun dengan metode Purposive Sampling.

\section{Stasiun I}

Stasiun ini merupakan daerah perairan yang sangat dangkal ketika air laut surut yang secara georafis terletak 037.196 LU-99⒋961 BT.

\section{Stasiun II}

Stasiun ini merupakan daerah dekat muara sungai Panggautan dan pemukiman penduduk secara geografis terletak 0 윽.738 LU-99⒋317 BT.

\section{Stasiun III}

Stasiun ini merupakan daerah dekat teluk dan jauh dari pemukiman penduduk yang secara geografis terletak $0 \cong 37.674$ LU-99⒋198 BT.

\section{Stasiun IV}

Stasiun ini merupakan daerah yang tidak terdapat pemukiman penduduk secara geografis terletak 037.759 LU-99⒋103 BT.

\section{Pengambilan Data \\ Pengambilan Sampel Makrozoobentos dan Tumbuhan Lamun}

Pengambilan sampel dilakukan dengan metode observasi langsung yang dilakukan pada waktu air laut surut agar tidak terkendala dengan arus dan gelombang untuk mempermudah pengambilan sampel makrozoobentos dan tumbuhan lamun. Dua garis transek yang ditarik tegak lurus kearah laut.Titik awal transek kuadran 1x1 m dimulai dari garis pantai sejauh 5 meter tegak lurus. Transek kuadrat kedua diambil dari titik akhir transek kuadrat pertama sejauh 5 meter. Jarak antara dua garis transek adalah 10 meter. Pengambilan sampel dilakukan dengan menggunakan sekop dengan bukaan $20 \times 20 \mathrm{~cm}$. Sampel yang telah diambil di saring dengan sieve net berukuran $1 \mathrm{~mm}$. Sampel tumbuhan lamun dan makrozoobentos diberi larutan alkohol $70 \%$ dan dilakukan identifikasi

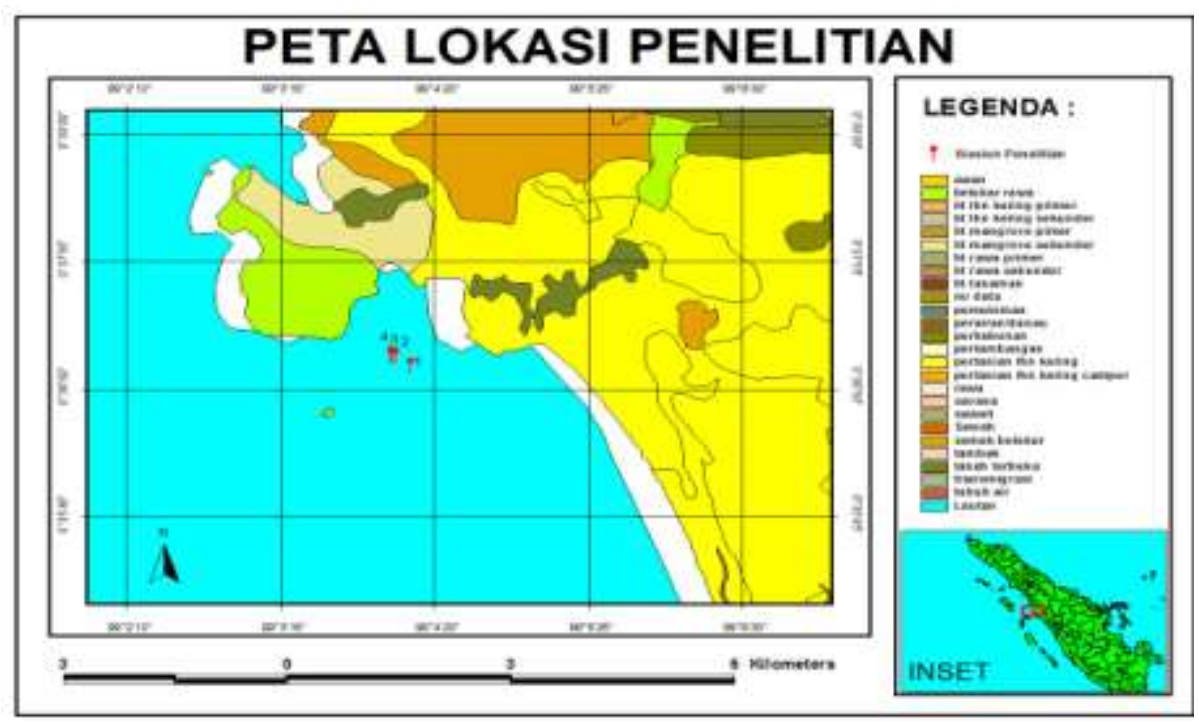

Sumber : Digitasi Bakosultanal,Bappada Sumut 2013 


\section{Pengambilan Data \\ Pengambilan Sampel Makrozoobentos dan Tumbuhan Lamun}

Pengambilan sampel dilakukan dengan metode observasi langsung yang dilakukan pada waktu air laut surut agar tidak terkendala dengan arus dan gelombang untuk mempermudah pengambilan sampel makrozoobentos dan tumbuhan lamun. Dua garis transek yang ditarik tegak lurus kearah laut.Titik awal transek kuadran 1x1 m dimulai dari garis pantai sejauh 5 meter tegak lurus. Transek kuadrat kedua diambil dari titik akhir transek kuadrat pertama sejauh 5 meter. Jarak antara dua garis transek adalah 10 meter. Pengambilan sampel dilakukan dengan menggunakan sekop dengan bukaan 20x20 $\mathrm{cm}$. Sampel yang telah diambil di saring dengan sieve net berukuran $1 \mathrm{~mm}$. Sampel tumbuhan lamun dan makrozoobentos diberi larutan alkohol $70 \%$ dan dilakukan identifikasi.

\section{Parameter Lingkungan Perairan}

Parameter lingkungan yang diukur yaitu suhu, kecepatan arus, derajat keasaman $(\mathrm{pH})$, oksigen terlarut (DO), salinitas, penetrasi cahaya yang dilakukan in situ pada setiap stasiun pengamatan. BOD, COD dilakukan di laboratorium.

Pengambilan sampel substrat dilakukan dengan membenamkan pipa paralon sedalam $\pm 20 \mathrm{~cm}$. Sampel Subtrat yang diambil $\pm 200 \mathrm{gr}$. Analisa jenis substrat dan kandungan organik dilakukan di Laboratorium Pertanian Universitas Sumatera Utara.

\section{Analsis Data}

Sampel yang telah diidentifikasi selanjutnya dianalisis dengan perasamaan sebagai berikut : Kepadatan Populasi (K), Kepadatan Relatif (KR), Frekuensi Kehadiran (FK), Dominansi, Indeks Keanekaragaman, Indeks Similaritas (IS) atau Indeks Kesamaan. Rumus persentase komposisi jenis lamun $\mathrm{P}=\frac{N i}{N} \times 100 \%($ Brower et al, 1990$)$

Dimana: $\mathrm{P}=$ Persentase setiap lamun (\%)

$\mathrm{Ni}=$ Jumlah setiap spesies $\mathrm{i}$,

$\mathrm{N}=$ Jumlah total seluruh spesies

Rumus kerapatan lamun:

$$
\mathrm{Di}=\mathrm{ni} / \mathrm{A} \text { (Blower et al,1990) }
$$

Dimana : $\mathrm{Di}=$ kerapatan jenis (ind $/ \mathrm{m}^{2}$ ),

ni= jumlah total tegakan dari jenis ke-i,

$\mathrm{A}=$ luas area plot pengamatan
Rumus persentase penutupan lamun :

$$
\mathrm{C}=\frac{\sum C i}{N} \text { (English et al, 1994) }
$$

dimana $\mathrm{C}=$ persen penutupan lamun, $\mathrm{Ci}=$ persen penutupan lamun

$\mathrm{N}=$ Jumlah plot transek setiap stasiun

\section{Analisis Statistik}

\section{Pengujian}

dilakukan dengan menggunakan uji statistic One-way ANOVA selanjutnya dilakukan uji lanjutan Uji Tukey. Analisis korelasi untuk mengetahui hubungan antara keanekaragaman makrozoobentos dengan penutupan lamun

\section{Hasil Dan Pembahasan}

Lamun dapat tumbuh pada kisaran 5$35^{\circ} \mathrm{C}$, dan tumbuh dengan baik pada kisaran suhu $25-30^{\circ} \mathrm{C}$ sedangkan pada suhu di atas $45^{\circ} \mathrm{C}$ lamun akan mengalami stres dan dapat mengalami kematian (McKenzie, 2008). Kecerahanan secara tidak langsung mempengaruhi kehidupan lamun karena berpengaruh terhadap penetrasi cahaya yang masuk ke perairan yang dibutuhkan oleh lamun untuk berfotosintesis. Cahaya merupakan faktor pembatas pertumbuhan dan produksi lamun di perairan pantai yang keruh (Hutomo, 1997).

Kecepatan arus di Pantai Natal berkisar 0,18$0,23 \mathrm{~m} / \mathrm{s}$ ketika pasang dan surut $0,19-0,25$ $\mathrm{m} / \mathrm{s}$.Kecepatan arus tertinggi terdapat pada stasiun I dan kecepatan arus terendah terdapat pada stasiun III dan IV. Arus pada perairan tersebut relatif tenang dan sedikit turbelensi. Kawuri et al (2012) melaporkan bahwa kecepatan arus mempengaruhi penyebaran pertumbuhan lamun dan makrozoobentos. Beberapa lamun dapat hidup pada kisaran salinitas 10-45\% (Hemminga dan Duarte, 2000). pH di ke empat stasiun masih memungkinkan untuk hidup Makrozoobentos. Air normal yang memenuhi syarat untuk suatu kehidupan mempunyai $\mathrm{pH}$ berkisar anatara 6,5-7,5 (Wardhana, 1994). Hasil penelitian menunjukkan kadar oksigen terlarut berkisar antara 7,6-7,8 mg/L, nilai ini tergolong baik, sesuai dengan KepMen LH Nomor 51 Tahun 2004 Tentang Baku Mutu Air Laut Untuk Biota Laut yang menyatakan bahwa kadar minimum oksigen terlarut $>5$ $\mathrm{mg} / \mathrm{L}$. 
Tabel 1. Pengukuran Parameter Kualitas Perairan Pantai Natal

\begin{tabular}{|c|c|c|c|c|c|c|c|}
\hline \multirow{2}{*}{ No } & \multirow{2}{*}{ Parameter } & \multirow{2}{*}{ Satuan } & \multicolumn{4}{|c|}{ Hasil } & \multirow{2}{*}{$\begin{array}{c}\text { Baku } \\
\text { Mutu * }\end{array}$} \\
\hline & & & ST1 & ST2 & ST3 & ST4 & \\
\hline 1. & Suhu & ${ }^{\mathrm{o}} \mathrm{C}$ & $28-30$ & $28-31$ & $28-30$ & $28-30$ & $28-30$ \\
\hline 2. & Penetrasi cahaya & $\mathrm{Cm}$ & 150 & 150 & 150 & 150 & 300 \\
\hline 3. & Kecepatan arus & $\mathrm{m} / \operatorname{det}$ & 0,25 & 0,20 & 0,18 & 0,18 & - \\
\hline 4. & Salinitas & $\%$ & $30-33$ & $30-32$ & $30-33$ & $30-33$ & $33-34$ \\
\hline 5. & $\mathrm{Ph}$ & - & 7,3 & 7,3 & 7,4 & 7,3 & $7-8,5$ \\
\hline 6. & DO & $\mathrm{mg} / \mathrm{L}$ & 7,4 & 7,8 & 7,7 & 7,3 & $>5$ \\
\hline 7. & $\begin{array}{l}\text { Kejenuhan } \\
\text { Oksigen }\end{array}$ & $\%$ & 97,3 & 102,5 & 101,2 & 96,0 & - \\
\hline 8. & $\mathrm{BOD}_{5}$ & $\mathrm{mg} / \mathrm{L}$ & 1,85 & 2,96 & 1,92 & 1,07 & 20 \\
\hline 9. & COD & $\mathrm{mg} / \mathrm{L}$ & 18,78 & 16,21 & 14,92 & 14,56 & - \\
\hline
\end{tabular}

Sumber : * KepMen LH Nomor 51Tahun 2004 tentang Baku Mutu Air Laut untuk Biota Laut

Nilai BOD selama pengamatan di perairan Natal menunjukkan kisaran 1,07-2,96 mg/L. Kisaran nilai BOD masih baik bagi kehidupan biota laut. Hal ini mengacu pada Kep MENLH No.51 tahun 2004 menetapkan ambang batas maksimum kandungan BOD bagi kehidupan laut adalah $20 \mathrm{mg} /$ L.Nilai COD yang didapat dari hasil pengamatan di perairan Natal berkisar antara 14,56-18,78 mg/L. Nilai ini tergolong dalam kisaran baik bagi biota laut. Apabila nilai COD tinggi maka hal ini manunjukkan bahwa bahan organik yang ada di perairan lebih banyak dalam bentuk yang sukar didegradasi secara biologis. Nilai COD di perairan yang tidak tercemar biasanya kurang dari $20 \mathrm{mg} / \mathrm{L}$ sedangkan di perairan tercemar dapat lebih dari $200 \mathrm{mg} / \mathrm{L}$ (Effendi, 2003).

Hasil analisis sampel struktur sedimen dari pantai Natal (Tabel 2), me-nunjukkan bahwa, kondisi substrat pada setiap plot lebih banyak didominasi oleh pasir. Secara keseluruhan nilai kandungan organik dari keempat stasiun ini tergolong rendah. Menurut Djaenuddin et al (1994) kandungan organik < 1\% dikategorikan sangat rendah, $1 \%-2 \%$ dikategorikan rendah, 2,01\%-3\% dikategorikan sedang, 3\%-5\% dikategorikan tinggi, dan $>5,01 \%$ dikategorikan sangat tinggi. Menurut effendi (2003) nitrat yang melebihi $0,2 \mathrm{mg} / \mathrm{L}$ dapat menyebabkan terjadinya eutrofikasi di perairan. Kadar fosfat yang didapat ini masih sesuai dengan kandungan fosfat yang umumnya dijumpai diperairan. Kandungan fosfat yang normal berdasarkan baku mutu air untuk biota laut Kepmen LH No 51 Tahun 2000 sebesar 0,015 $\mathrm{mg} / \mathrm{L}$.

Tabel 2. Hasil Analisis Sedimen

\begin{tabular}{cccccc}
\hline Paramet & Satu & \multicolumn{4}{c}{ Stasiun Pengamatan } \\
\cline { 3 - 6 } er & an & I & II & III & IV \\
\hline \multirow{2}{*}{ Pasir } & $\%$ & 53,8 & 51,8 & 45,8 & 53,8 \\
& & 4 & 4 & 4 & 4 \\
\hline
\end{tabular}

\begin{tabular}{cccccc}
\hline Debu & $\%$ & 18,5 & 24,5 & 22,5 & 26,5 \\
& & 6 & 6 & 6 & 6 \\
Liat & $\%$ & 27,6 & 23,6 & 31,6 & 19,6 \\
Tekstur & ----- & Llip & Llip & Llip & Lp \\
C- & $\%$ & 1,23 & 1,10 & 1,40 & 1,12 \\
organik & & & & & \\
Nitrat & $\mathrm{mg} /$ & 0,15 & 0,13 & 0,15 & 0,15 \\
& $\mathrm{~L}$ & & & & \\
Fosfat & $\mathrm{mg} /$ & 0,01 & 0,01 & 0,01 & 0,01 \\
& $\mathrm{~L}$ & 4 & 2 & 2 & 2 \\
\hline
\end{tabular}

Keterangan :

Llip = Lempung liat berpasir

Lp = Lempung berpasir

\section{Tumbuhan Lamun}

Hasil penelitian menunjukkan terdapat 4 spesies lamun yang hidup disekitar perairan pantai Natal yaitu Enhalus acoroides, Halophila ovalis, Halodule pinifolia, dan Cymodecea rotundata. Tabel 3 menunjukkan ada dua stasiun pengamatan yang hanya terdapat satu jenis lamun yaitu pada stasiun I dan

II. Stasiun I memilki kondisi perairan lebih dangkal. Cymodocea rotundata dapat tumbuh di daerah dangkal saat air surut mencapai kedalaman kurang dari 1 meter saat surut terendah dan menyukai perairan yang terpapar sinar matahari (Kiswara,1997).

Tabel 3. Persentase Komposisi Jenis Lamun di Perairan Pantai Natal

\begin{tabular}{clcccc}
\hline $\mathrm{N}$ & $\begin{array}{l}\text { Nama } \\
\mathrm{O}\end{array}$ & $\mathrm{ST} 1$ & $\mathrm{ST} 2$ & $\mathrm{ST} 3$ & $\mathrm{ST} 4$ \\
$\mathbf{1}$ & $\begin{array}{l}\text { Enhalus } \\
\text { acoroides }\end{array}$ & - & 100 & 32,11 & 34,69 \\
$\mathbf{2}$ & $\begin{array}{l}\text { Halophila } \\
\text { ovalis }\end{array}$ & - & - & 35,96 & 35,81 \\
$\mathbf{3}$ & $\begin{array}{l}\text { Cymodecea } \\
\text { rotundata }\end{array}$ & 100 & - & 14,31 & 11,32 \\
$\mathbf{4}$ & $\begin{array}{l}\text { Halodule } \\
\text { pinifolia }\end{array}$ & - & - & 17,61 & 18,18 \\
\hline
\end{tabular}




\begin{tabular}{l}
\hline Total 100100100100 \\
\hline Stasiun II merupakan kawasan yang \\
berdekatan dengan muara sungai Panggautan \\
menyebabkan daerah ini menerima banyak \\
masukan air tawar, sehingga salinitas di kawasan \\
ini cenderung lebih sering berubah-ubah. Tingkat \\
kekeruhan yang tinggi juga diduga menjadi \\
penyebab tidak ditemukannya lamun dari jenis \\
yang lain hidup disini. Hal yang sama juga \\
disampaikan oleh Bengen (2001) menjelaskan \\
bahwa Enhalus acoroides merupakan lamun yang \\
tumbuh pada substrat berlumpur dari perairan \\
keruh dan dapat membentuk jenis tunggal, atau \\
mendominasi komunitas padang lamun. \\
Stasiun III dan IV mempunyai kedalaman \\
250-220 cm. Stasiun III dan IV ini dijumpai jenis \\
lamun yaitu Enhalus acoroides, Halophila ovalis, \\
Halodule pinifolia, dan Cymodecea rotundata. Ke \\
empat jenis lamun ini dapat tumbuh di daerah \\
dengan kedalam sedang atau daerah pasang \\
surut dengan kedalaman perairan berkisar \\
antara 100-500 cm (Kiswara, 1997).
\end{tabular}

Tabel 4. Kerapatan Jenis Lamun

\begin{tabular}{clcccc}
\hline $\mathbf{N}$ & Nama & ST & ST & ST & ST \\
$\mathbf{0}$ & Spesies & $\mathbf{1}$ & $\mathbf{2}$ & $\mathbf{3}$ & $\mathbf{4}$ \\
\hline $\mathbf{1}$ & $\begin{array}{l}\text { Enhalus } \\
\text { acoroides }\end{array}$ & - & 30,2 & 35 & 37,4 \\
$\mathbf{2}$ & $\begin{array}{l}\text { Halophila } \\
\text { ovalis } \\
\text { Cymodecea } \\
\mathbf{3}\end{array}$ & - & - & 39,2 & 38,6 \\
$\mathbf{4}$ & $\begin{array}{l}\text { Hatundata } \\
\text { Halodule } \\
\text { pinifolia }\end{array}$ & - & - & 19,2 & 19,6 \\
\hline
\end{tabular}

Stasiun I didominasi oleh jeni Cymodecea rotundata, tingginya frekuensi kerapatan jenis Cymodocea rotundata menunjukkan jenis ini dapat menyesuaikan diri dengan karakteristik habitat perairan pantai Natal, jenis lamun ini sering ditemukan di daerah dangkal hingga daerah yang terekspos ketika air laut surut. Hasil penelitian menunjukkan bahwa jenis Enhalus acoroides dapat ditemukan pada tiga stasiun penelitian, yaitu pada stasiun II, III, dan IV dengan kerapatan yang cenderung sama yaitu berada pada kisaran 24,6-34,7 Ind/ $\mathrm{m}^{2}$, hal ini menunjukkan bahwa jenis ini dapat beradaptasi dengan lingkungan sekitar perairan pantai Natal. Substrat pada stasiun II, III, dan IV yang berjenis lempung liat berpasir dan lempung berpasir sangat cocok bagi Enhalus acoroides.Sangaji (1994) menyatakan bahwa Enhalus acoroides dominan hidup pada substrat dasar berpasir dan pasir sedikit bercampur lumpur dan kadang-kadang terdapat dasar yang terdiri dari campuran pecahan karang yang telah mati. Enhalus acoroides juga lebih tahan terhadap kekeruhan dibandingkan dengan spesies yang lain. Menurut Bengen (2001) menyatakan bahwa Enhalus acoroides merupakan lamun yang tumbuh pada substrat berlumpur dari perairan keruh dan dapat membentuk jenis tunggal, atau mendominasi komunitas padang lamun. Jenis Enhalus acoroides memiliki toleransi untuk perubahan suhu, salinitas dan jenis substrat lebih luas dibanding jenis lainnya (Poedjirahajoe et al. 2013).

Jenis Halophila ovalis dan Halodule pinifolia hanya terdapat pada dua stasiun penelitian yaitu pada stasiun III dan IV. Kerapatan kedua jenis ini hampir sama dikedua stasiun penelitian ini menunjukkan bahwa kondisi lingkungan stasiun III dan IV sangat baik untuk kehidupan kedua jenis lamun ini.

Persentase tutupan lamun tertinggi berada pada stasiun IV, sedangkan persentase tutupan lamun terendah terdapat pada stasiun II. Menurut Dahuri et al (2004) luas tutupan dan sebaran lamun dapat dipengaruhi ketersediaan nutrien pada substrat yang tidak merata sehingga lamun hanya tumbuh pada titik tertentu. Kondisi stasiun 1 tergolong kurang sehat/kurang kaya, stasiun 2 tergolong miskin/tidak sehat, stasiun 3 dan 4 tergolong kaya/sehat. Hal ini sesuai dengan KEPMEN-LH Nomor 200 tahun 2004 yang menyatakan bahwa kondisi ekosistem lamun yang sehat/kaya memiliki persen tutupan $\geq 60 \%$, kurang sehat/kurang kaya 30-59,9\%, sedangkan miskin/rusak memiliki persen tutupan $\leq 29,9 \%$.

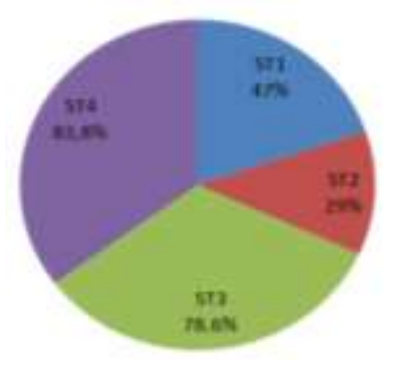

Gambar 2. Persentase Tutupan Lamun pada Stasiun Penelitian

\section{Nilai Kepadatan populasi, Kepadatan Relatif, Frekuensi Kehadiran Makro-zoobentos}

\begin{tabular}{cccc}
\multicolumn{2}{c}{ Hasil penelitian yang dilakukan di } \\
perairan Natal diperoleh 16 jenis
\end{tabular} makrozoobentos yang terdapat di ekosistem lamun perairan Natal.Jenis kerang-kerangan (Bivalvia) memiliki nilai Kepadatan Populasi (K), Kepadatan Relatif (KR) dan Frekuensi Kehadiran (FK) tertinggi pada stasiun I, II, dan IV. Stasiun I dan IV jenis Anadara antiquata menjadi jenis yang paling sering dijumpai. Tingginya Nilai $\mathrm{K}$, 
KR dan FK pada jenis kerang-kerangan ini dapat dikaitkan dengan berbagai faktor fisika kimia, seperti jenis substrat yang didominasi oleh pasir (Tabel 2), hal ini didukung oleh pernyataan Lind (1979) yang menyatakan bahwa substrat pasir merupakan habitat yang paling disukai makrozoobentos.

\section{Indeks Dominansi, Keanekaragaman, dan} Keseragaman

Tabel 5 menunjukkan bahwa koefisien indeks dominansi mendekati 0 , sesuai pernyataan Odum (1993) tidak ditemukannya spesies yang men-dominasi di setiap stasiun, ini berarti bahwa kondisi lingkungan ekosistem perairan pantai Natal masih tergolong baik, karena masih banyak spesies yang dapat beradaptasi dengan baik pada ekosistem ini. Hasil analisis menunjukkan tingkat keanekaragaman makro-zoobentos pada perairan pantai Natal tergolong pada tingkat keanekaragaman sedang, dimana koefisien $\mathrm{H}^{\prime}$ bernilai lebih dari 2,30 sesuai dengan pernyataan Krebs (1978) dimana apabila nilai $\mathrm{H}^{\prime} 0<\mathrm{H}^{\prime}<2,30$ keanekaragaman tergolong rendah, 2,30< $<\mathrm{H}^{\prime}<6,90$ keanekaragaman tergolong sedang, dan $\mathrm{H}^{\prime}>6,90$ keanekaragaman tergolong tinggi. Keanekaragaman tergolong sedang menunjukkan bahwa kondisi lingkungan perairan cukup mendukung bagi kehidupan makrozoobentos.

Analisis indeks keseragaman menunjukkan bahwa koefisien J' mendekati 1, hal ini berarti bahwa jumlah individu setiap spesies adalah sama, atau tidak ada jenis terentu yang lebih banyak ditemukan pada satu kawasan area pengamatan.

Tabel 5. Nilai Indeks Dominansi, Keanekaragaman, dan Keseragaman

\begin{tabular}{cccccc}
\hline $\mathrm{N}$ & \multirow{2}{*}{ Indeks } & \multicolumn{4}{c}{ Stasiun } \\
\cline { 3 - 6 } $\mathrm{o}$ & & 1 & 2 & 3 & 4 \\
\hline 1 & Dominansi & 0,0 & 0,2 & 0,0 & 0,0 \\
& $(\mathrm{C})$ & 9 & 2 & 9 & 9 \\
2 & Keanekaraga & 2,5 & 2,5 & 2,5 & 2,5 \\
& man (H') & 5 & 9 & 2 & 3 \\
3 & Keseragaman & 0,9 & 1,0 & 0,9 & 0,9 \\
& $\left(\mathrm{~J}^{\prime}\right)$ & 2 & 8 & 3 & 3 \\
\hline
\end{tabular}

Tabel 6. Nilai Indeks Similaritas (Kesamaan)

\begin{tabular}{|c|c|c|c|c|}
\hline Stasiun & 1 & 2 & 3 & 4 \\
\hline 1 & - & 84,61 & 96,55 & 96,55 \\
\hline 2 & - & - & 88,00 & 88,00 \\
\hline 3 & - & - & - & 100,00 \\
\hline
\end{tabular}

Hasil pengamatan menunjukkan bahwa nilai indeks similaritas dikategorikan memiliki kesamaan tinggi

Kesamaan ini karena faktor ekologi dan faktor fisik kimia yang hampir sama antara stasiun tersebut. Kondisi yang hampir sama menyebabkan terdapat kesamaan nilai spesies pada setiap stasiun tersebut sangat mirip.

\section{Analisis Stastistik}

Hasil analisis menunjukkan adanya perbedaan yang nyata pada keanekaragaman makrozoobentos antar stasiun pengamatan (P $<0,05)$. Perbedaan ini menunjukkan bahwa setiap stasiun penelitian memiliki perbedaan karakteristik. Keanekaragaman yang tinggi menunjukkan semakin besarnya keragaman dan proporsi masing-masing jenis yang semakin merata.

Hasil analisis korelasi Pearson antara keragaman makrozoobentos dengan tutupan lamun menunjukkan bahwa koefisien korelasi bernilai $-0,949$ ini berarti hubungan antara tutupan lamun dengan keanekaragaman makrozobentos di kawasan ini sangat kuat berlawanan arah artinya semakin tinggi tutupan lamun semakin rendah keanekragaman makrozoobentos. Tingginya persentase tutupan lamun tidak selalu diikuti oleh tingginya keanekaragaman makrozobentos di kawasan tersebut.

Hemminga dan Duarte (2000) menyatakan juga bahwa keberadaan suatu jenis makrozoobentos di daerah lamun tidak sepenuhnya bergantung pada vegetasi lamun. Faktor lingkungan fisika, kimia, maupun biologi memiliki pengaruh terhadap keberadaan suatu jenis makrozoobentos di daerah lamun. Makrozoobentos. Jenis bivalvia dan gastropoda pada umumnya ditemukan pada substrat dasar sementara organisme lainnya hanya tinggal sementara sebagai tempat mencari makan dan perlindungan dari peredator. Hal yang sama juga diungkapkan Ilahi et al, (2013) bahwa kelimpahan dan keanekaragaman makrobentos hanya ditentukan $12 \%$ oleh kerapatan lamun, sebaliknya $88 \%$ ditentukan oleh faktor lain, termasuk fisik kimia perairan. Menurut Peterson \& Heck (2001) bahwa bivalvia yang hidup di lamun memiliki ukuran tubuh yang lebih besar dibandingkan dengan yang hidup di daerah tanpa lamun.

\section{Kesimpulan}

Dari hasil penelitian dapat disimpulkan beberapa hal : 
1. Kondisi ekosistem lamun pantai Natal tergolong sehat dengan rata-rata tutupan lamun $\geq 60 \%$. Terdapat 4 jenis lamun yang hidup di perairan pantai Natal yaitu Cymodecea rotundata, Enhalus acoroides, Halophila ovalis, Halodule pinifolia.

2. Terdapat 16 jenis makozobentos yang hidup pada kawasan ekosistem lamun pantai Natal. Indeks Keane-karagaman makrozobentos di ekosistem lamun pantai Natal berada pada kondisi sedang $\left(\mathrm{H}^{\prime}=2,329-2,593\right)$.

3. Korelasi yang sangat kuat terjadi antara keragaman makrozoobentos dengan tutupan lamun dengan nilai $-0,949$

\section{Daftar Pustaka}

Bengen, D.G. 2001. Ekosistem dan Sumberdaya Alam Pesisir Laut. Pusat Kajian Sumberdaya Pesisir dan Lautan IPB.

Brouns JJWM \& Heijs FML. 1986. Tropical seagrass ecosystem in Papua New Guinea a general account of the environment, Marine Flora and Fauna. Proc. K. Ned. AKAD.

Brower J E, H Z Jerrold, CN Von Ende. 1990. Field and Laboratory Methods for General Ecology.Thrid Edition.USA Wm.C.Brown Publisher. New York.

Dahuri, R. 2004. Pengelolaan Sumber Daya Wilayah Pesisir dan Lautan Secara Terpadu, Edisi Revisi. Pradnya Paramita. Jakarta.

Dharma B. 1988. Siputdan Kerang Indonesia. PT Sarana Graha. Jakarta

DenHartog C. 1970. The Sea Grassesof the Word. Nort Hollad Publishing Company.

Effendi H. 2003.Telaah Kualitas Air bagi Pengelolaan Sumber daya dan Lingkungan Perairan. PenerbitKanisius. Yogyakarta.

Hemminga MA, Duarte CM. 2000. Seagrass Ecology. London-United Kingdom (UK): Cambridge University Press.
Hutomo H. 1997. Padang lamun Indonesia : salah satu ekosistem laut dangkal yang belum banyak dikenal Puslitbang OseanologiLIPI. Jakarta. 35 pp.

Keputusan Menteri Negara Lingkungan Hidup (KEPMEN-LH) Nomor 51 Tahun 2004. Baku Mutu Air laut.

Keputusan Menteri Negara Lingkungan Hidup (KEPMEN-LH)) Nomor 200 Tahun 2004. Kriteria Baku Kerusakan dan Pedoman Penentuan Status Padang Lamun.

Kiswara W. 1999. Komunitas Padang Lamun di Sumatera Utara. Prosiding Seminar Kelautan Regional Sumatera Utara. Fakultas Perikanan Universitas Bung Hatta Padang.

Lind O T, 1979. Hand Book of Common Method in Lymnology. Second Edition. The C.V. Mosby Company St. Louis. Toronto. London.

McKenzie L. 2008. Seagrass Educators Handbook. Northern Fisheries Centre. Australia $(\mathrm{AU})$.

Odum E P 1993. Dasar-dasar Ekologi diterjemahkan oleh T. Samingan. Gadjah Mada Universty Press. Yogyakarta

Peterson J B, Heck KL. 2001. Positive Interaction Between Suspension-Feeding Bivalves and Seagrass Facultative Mutualism. Marine Ecology Progress.

Sangaji, F. 1994. Pengaruh Sedimen dasar terhadap Penyebaran, Kepadatan, Keanekaragaman dan Pertumbuhan Padang Lamun di Laut Sekitar Pulau Barang Lompo. Tesis, Pascasarjana, Universitas Hasanudin. Ujung Pandang.

Susetiono. 2004. Fauna Padang Lamun Tanjung Merah Selat Lembah. Jakarta. Pusat Penelitian 